\title{
Kinematics motion of paddy in hot air pulse flow
}

\author{
Nuttapong Wongbubpa ${ }^{1 *}$, Krawee Treeamnuk ${ }^{1}$, and Tawarat Treeamnuk $^{2}$ \\ ${ }^{1}$ Suranaree University of Technology, School of Mechanical engineering, Thailand \\ ${ }^{2}$ Suranaree University of Technology, School of Agricultural engineering, Thailand
}

\begin{abstract}
This research aims to study the characteristic of paddy motion under the hot air pulse flow in the drying tube length $2 \mathrm{~m}$ by using the kinematics motion analysis. The equations of paddy motion are analyzed to evaluate the pattern of paddy motion, total distance that the paddy can travel through the drying tube and Reynolds number of paddy. Results found that Model I, II and III consume the paddy travel time of approximately 1.3, 5.0 and $2.2 \mathrm{~s}$ and give a total distance of $2.6,2.7$ and $2.5 \mathrm{~m}$ and they have maximum travel velocity of $4.12,1.37$ and $1.85 \mathrm{~m} / \mathrm{s}$ respectively. When considering the Reynolds number, the models I, II and III give the most values from similar calculations with $1,837,1,816$ and 1,821 respectively. Based on various parameters from all of models, Model III was the closest characteristic of paddy motion to the actual movement in the system.
\end{abstract}

\section{Introduction}

Currently, the technique of increasing the heat transfer rate in hot air dryer is very important especially in agricultural products drying. A usual method is divided into 3 types [1] such as 1) Active technique is the use of external energy to stimulate fluid shaking or the vibrating of surface material. 2) Passive technique is the use of self-generated energy such as adding the roughening or a device to create an un-uniform fluid flow. 3) Compound technique is a combination of Active and Passive techniques. The most popular method for increasing heat transfer rate is a passive technique because it is convenient and cost effective. Many researchers invented the passive heat transfer equipment by inserting a special device inside the heat exchanger tube or drying tube such as inserting twisted tape to generate a whirl flow. $[2,3]$ inserting a wire coil [4] inserting a twisted cross-baffle [5] inserting quadruple perforated-delta-winglet pairs [6] etc. But these techniques that inserted devices in tube are responsibly blocking the fluid flow. Bhuiya et al. [7] conducted experiments to compare the heat transfer in the heat exchanger tubes between the smooth wall pipes and inserting a twisted tape in pipes, which have 4 porosity ratios $\left(R_{P}=1.6,4.5,8.9\right.$ and $\left.14.7 \%\right)$. It found that the twisted tape can increase the heat transfer more than the smooth wall pipe but, it also increases the friction factor too. Bhuiya et al. [8] performed experiments by inserting double counter twisted tape in a heat exchanger tube to study the performance of heat exchangers in circular pipes. From the study, the torsion of 1.95 distortion gave the highest thermal performance of 1.35. Skullong et al. [9] Study the flow and heat transfer behavior using experimental methods and numerical simulations by inserting delta-wing tape with 3 angles.

* Corresponding author: Nuttapong1441.W@gmail.com 
$\left(\alpha=30^{\circ}, 45^{\circ}\right.$ and $\left.60^{\circ}\right)$ From the study, it was found that the wing case with an angle of $60^{\circ}$ gives the highest heat transfer and flow resistance. While the wing angle is $30^{\circ}$, thermal performance is highest and the wing implantation in the heat exchanger provided higher heat transfer values as well as higher thermal performance than wire coil and twisted tape. Although the use of device inserted can increase the rate of heat transfer in the fluid, but it results in obstruction of the fluid flow and increases the load on the flow system too. This article objective was to present the new concept of heat transfer increasing technique in the hot air - paddy drying tube. This concept provided passive heat transfer technique by implemented a pulsing air flow through the vertical drying tube. Higher drying rate and reducing of mechanical losses of paddy are expected from this new concept method because paddy will free flow up and down without impacting with the inserted object throughout the drying process.

\section{Methods}

\subsection{Pneumatic paddy dryer}

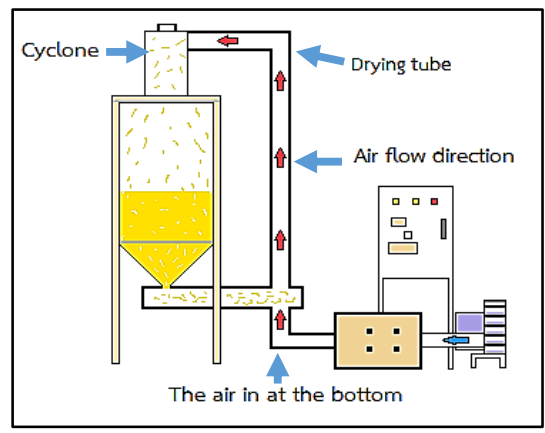

Fig. 1. Pneumatics paddy dryer.

This research studied the motion equations of paddy in vertical drying tube with a length of $2 \mathrm{~m}$ in pneumatic paddy dryer (Figure 1). The paddy (yellow symbol) is taken out of the bin by a screw conveyor for feed into the drying tube. A hot air is charged into the drying tube from the bottom and blow up a paddy to flow like a fluid. This process causes the heat and moisture transfer between paddy and hot air in the tube and provides the drying of paddy. Moist air is separated from the dried paddy by cyclone after that, the paddy will fall to the bin and recirculate the process again until the paddy is reached the needed moisture.

Faij paddy [10] was used as a sample of moist paddy for the pneumatics dryer. Some physical properties including of mass, length, width and thickness at humidity $25 \% \mathrm{wb}$ of paddy are taken to calculate for the Geometric mean diameter (D), Frontal area $\left(\mathrm{A}_{f}\right)$ and Volume of paddy (V) [10] as shown in the following Equation (1) - (3).

$$
\begin{aligned}
& D=(L W T)^{1 / 3} \\
& A_{f}=\left(\frac{\pi}{4}\right) W L \\
& V=A_{f} L
\end{aligned}
$$

where $\mathrm{L}$ is the length $(\mathrm{mm}) . \mathrm{W}$ is the width $(\mathrm{mm}) . \mathrm{T}$ is the thickness $(\mathrm{mm})$. 


\subsection{Kinematics analysis of the paddy motion}

Motion of paddy under pulse flow that hot air in the drying tube that was generated by open and close the air flow control valve by a pulse pattern. The motion of paddy begins at the feed point inside the drying tube (zero meter position in Figure $2 b$ ) and the time is set to zero second at this point. If the kernel is floated by hot air blowing, this stage is called air supplying (AS) period. On the other hand, when the hot air blowing is paused and cause falling of kernel, this stage called air supplying outage (AO) period. The movement characteristics of paddy are shown in Figure $2 \mathrm{~b}$. Free body diagram of force acted on paddy shown that the single kernel paddy can floats from the bottom to the top of the drying tube and the paddy must have an acceleration overcome the gravity as shown in Figure 2a. From the Newton's second laws, the sum of the Buoyance force $\left(F_{B}\right)$, Drag force $\left(F_{D}\right)$ and weight $(\mathrm{mg})$ applied on the paddy is equal to mass of paddy $(\mathrm{m})$ multiply by an acceleration of motion (a) [11]. An acceleration of paddy (a), $F_{B}$ and $F_{D}$ can calculate by Equation (4) - (6).

$$
\begin{gathered}
a=\frac{-m g+F_{B}+F_{D}}{m} \\
F_{B}=\rho g V \\
F_{D}=\frac{1}{2} C_{D}\left[\rho\left(v_{\text {air }}\right)^{2} A_{f}\right]
\end{gathered}
$$

where $\rho$ is the density of air $\left(\mathrm{kg} / \mathrm{m}^{3}\right), g$ is the gravity $\left(\mathrm{m} / \mathrm{s}^{2}\right), V$ is the volume of paddy $\left(\mathrm{m}^{3}\right)$, $C_{D}$ is drag coefficient [10] of paddy, $v_{\text {air }}$ is the velocity of air $(\mathrm{m} / \mathrm{s})$.

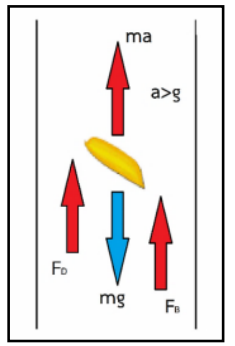

(a)

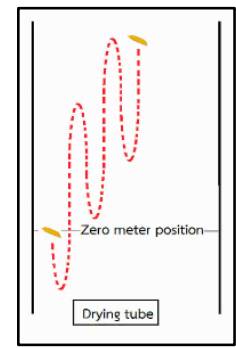

(b)

Fig. 2. a) Free body diagram of forces act on paddy while floating in the air stream.

b) Path of motion of paddy in the pulse flow drying tube.

The assumptions of the model consist of: The movement of the paddy is in twodimensional. The air velocity distribution in the drying tube is uniform with isothermal flow and neglect the wall friction. The kinematics motion of paddy in drying tube is divided analyzed into 3 models as follows.

Model I: Classical Physics motion requires that the object is moving under constant gravity (g) with the influent of $F_{D}$ and $F_{B}$ and neglected the relative velocity between paddy and air stream in drying tube. Acceleration of paddy in this period is equal to the gravity force $(a=g)$. The velocity (v) and moving distance ( $\mathrm{s}$ ) of paddy in AS period are evaluated with the Equation (7) and (8) and for AO period are evaluated with Equation (9) and (10).

$$
\begin{aligned}
& v_{i+1}=v_{i}+a t \\
& s_{i}=v_{i} t+\frac{1}{2}\left(a t^{2}\right) \\
& v_{i+2}=v_{i+1}+a t \\
& s_{i+1}=s_{i}+v_{i+1} t+\frac{1}{2}\left(a t^{2}\right)
\end{aligned}
$$


Model II: Kinematics motion under the influence of air velocity (vair) that was affected on $F_{D}$ force. It executes acceleration of the system unstable. Acceleration (a), velocity (v) and moving distance (s) of paddy in AS period are evaluated with the Equation (11), (12) and (13).

$$
\begin{aligned}
& a=\frac{F_{B}+\frac{1}{2} C_{D}\left[\rho\left(v_{i+1}\right)^{2} A_{f}\right]-m g}{m} \\
& v_{i+1}=v_{i}+a t \\
& s_{i}=v_{i} t+\frac{1}{2}\left(a t^{2}\right)
\end{aligned}
$$

For AO period a, v and s are evaluated with Equation (14), (15) and (16).

$$
\begin{aligned}
& a=\frac{F_{B}+\frac{1}{2} C_{D}\left[\rho\left(v_{a i r}-v_{i+1}\right)^{2} A_{f}\right]-m g}{m} \\
& v_{i+2}=v_{i+1}+a t \\
& s_{i+1}=s_{i}+v_{i+1} t+\frac{1}{2}\left(a t^{2}\right)
\end{aligned}
$$

Model III: Kinematics of relative motion between paddy and air velocity under influence of air velocity. In this situation the acceleration is unstable because the vair and velocity (v) of paddy in AS period equations must be replaced by the relative velocity between $\mathrm{v}$ and $\mathrm{Vair}$ This model can truly express the motion of paddy in drying tube and the acceleration (a), velocity (v) and moving distance (s) of paddy in AS period are evaluated with the Equation (17), (18) and (19).

$$
\begin{aligned}
& a=\frac{F_{B}+\frac{1}{2} C_{D}\left[\rho\left(v_{i+1}\right)^{2} A_{f}\right]-m g}{m} \\
& v_{i+1}=v_{i}+a^{(\Delta t)} \\
& s_{i+1}=s_{i}+v_{i}(\Delta t)+\frac{1}{2}\left[a(\Delta t)^{2}\right]
\end{aligned}
$$

For AO period a, v and s are evaluated with Equation (20), (21) and (22).

$$
\begin{aligned}
& a=\frac{F_{B}+\frac{1}{2} C_{D}\left[\rho\left(v_{a i r}-v_{i+1}\right)^{2} A_{f}\right]-m g}{m} \\
& v_{i+1}=v_{i}+a(\Delta t) \\
& s_{i+1}=s_{i}+v_{i}(\Delta t)+\frac{1}{2}\left[a(\Delta t)^{2}\right]
\end{aligned}
$$

where $s_{i+1}$ and $s_{i}$ are the current position and initial position of the moving paddy $(\mathrm{m}), v_{i}$ is the initial velocity of the paddy $(\mathrm{m} / \mathrm{s}), v_{i+1}$ and $v_{i+2}$ is the changing velocity of the paddy $(\mathrm{m} / \mathrm{s}), t$ is the current time (s) and $\Delta t$ is the difference time between the current and initial time (s).

Due to the paddy kernel move up and down along the tube throughout the drying period. Resulting in the total distance ( $s_{\text {total }}$ ) of the paddy movement is greater than the tube length and consider according to the Equation (23).

$$
s_{\text {total }}=\sum_{i=1}^{n}\left|s_{i}\right|
$$

where $i$ is the changing of order of the motion and $n$ is the total of motions throughout considering time.

The equations of paddy motion in the pulse flow of hot air are analyzed to evaluate the pattern of paddy motion, total distance that the paddy can travel through the drying tube and Reynolds number of paddy by Equation (24). 


$$
R e=\frac{\rho(\Delta v) D}{\mu}
$$

where $\Delta v$ is the relative velocity between the drying air and the velocity of the paddy kernel $(\mathrm{m} / \mathrm{s})$ and $\mu$ is the viscosity of the air $(\mathrm{kg} / \mathrm{m}-\mathrm{s})$.

All of equations was created as a set of AS period and AO period on the spread sheet computer program. Consider that the velocity of hot air at $80^{\circ} \mathrm{C}$ entering to drying tube is $9 \mathrm{~m} / \mathrm{s}$. Schedule of AO period per AS period is $0.15 \mathrm{~s}$ and $0.75 \mathrm{~s}$ respectively.

\section{Results and Discussion}

\subsection{Position and velocity of paddy during the time}

When the paddy kernel travels under pulse flow of hot air supply the calculated results of 3 models show that in AO period paddy falling down. In AS period, the paddy will be push to float by the air stream and moving up again. This behavior of the paddy movement will be repeated in same pattern until reach the top end of the tube length. The motion of kernel from 3 models are trendy interval increasing as show in Figure 3, 4 and 5. On the AO period, all of velocity from 3 models will decrease with proportional constant slope. On the AS period, Model I give a proportional slope trend line during the time because it is only under the influenced constant gravity. Model II and III are curvature increasing in trend line because the influence of $F_{B}$ on the acceleration of kernel. The effect of relative velocity between $v$ and $v_{\text {air }}$ on the motion gives the higher velocity of paddy more than model II and the period time of rising - fall look similar model I but the travel time of paddy is quit long more than model I when is reach the top end of tube. The values of $\mathrm{s}$ and $\mathrm{v}$ from model I, II and III show in Figure 3, 4 and 5.

\subsection{Reynolds number of paddy kernel}

The results found that Reynolds number affected by the movement of paddy. When the kernel start moves by falling on the first, Reynolds number will increase in small increments. Because the velocity increases by the gravity. On the AS period, the air stream will be run opposite the direction of kernel motion that causing the large difference value of relative velocity between paddy and air stream. This effect provides the highest increasing of Reynolds number of paddy kernel in that position in the tube. Reynold numbers of all models show in Figure 6, 7 and 8.

\subsection{Total distance of paddy in the drying tube}

From the results (Figure 9), it found that the charging of pulse flow of hot air into the drying tube can affects to increase the total distance of the paddy to long more than the tube length. Considering the tube length $2 \mathrm{~m}$. Model I, II and III consume the paddy travel time of approximately 1.3, 5.0 and $2.2 \mathrm{~s}$ respectively and give a total distance of $2.6,2.7$ and $2.5 \mathrm{~m}$. respectively. 


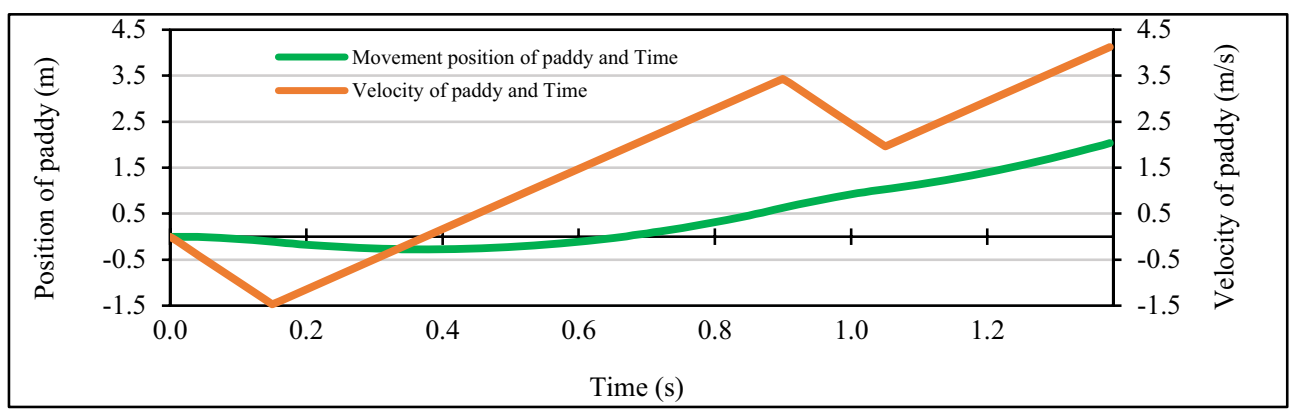

Fig. 3. The position and velocity of paddy during the travel time. (Model I)

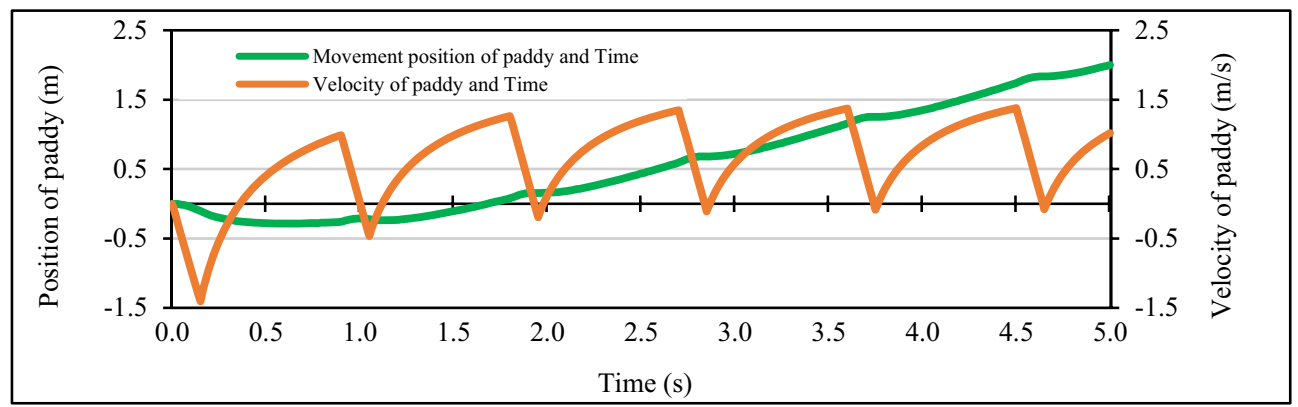

Fig. 4. The position and velocity of paddy during the travel time. (Model II)

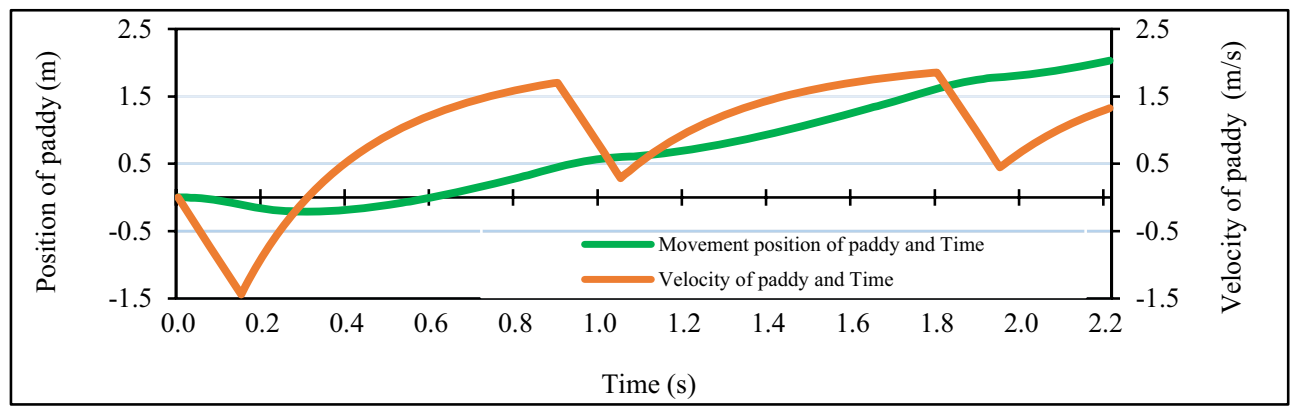

Fig. 5. The position and velocity of paddy during the travel time. (Model III)

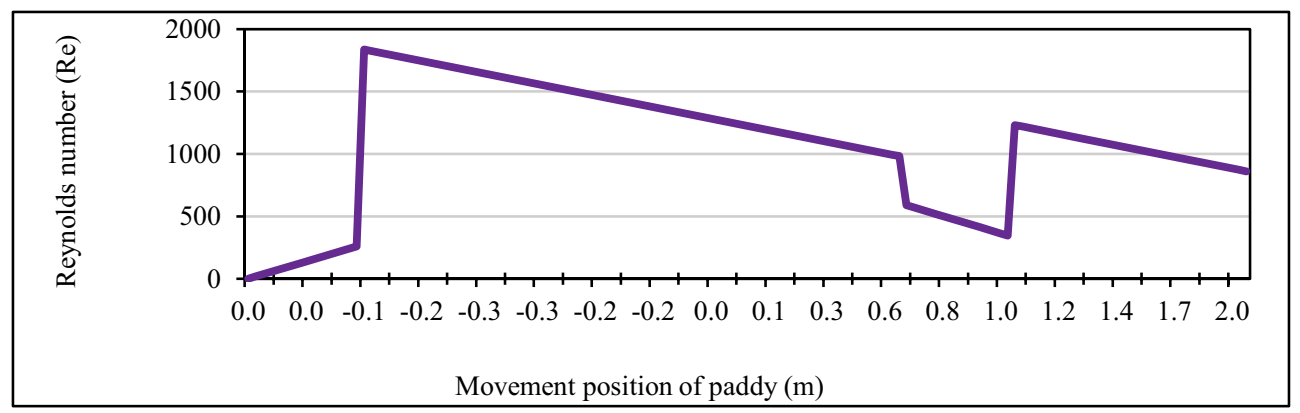

Fig. 6. Reynold Number of paddy during the distance in the tube. (Model I) 


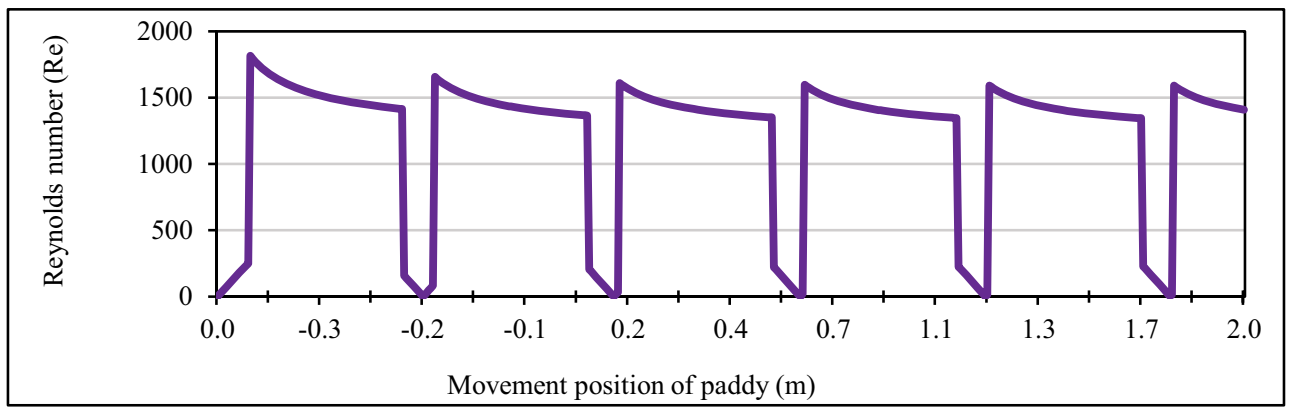

Fig. 7. Reynold Number of paddy during the distance in the tube. (Model II)

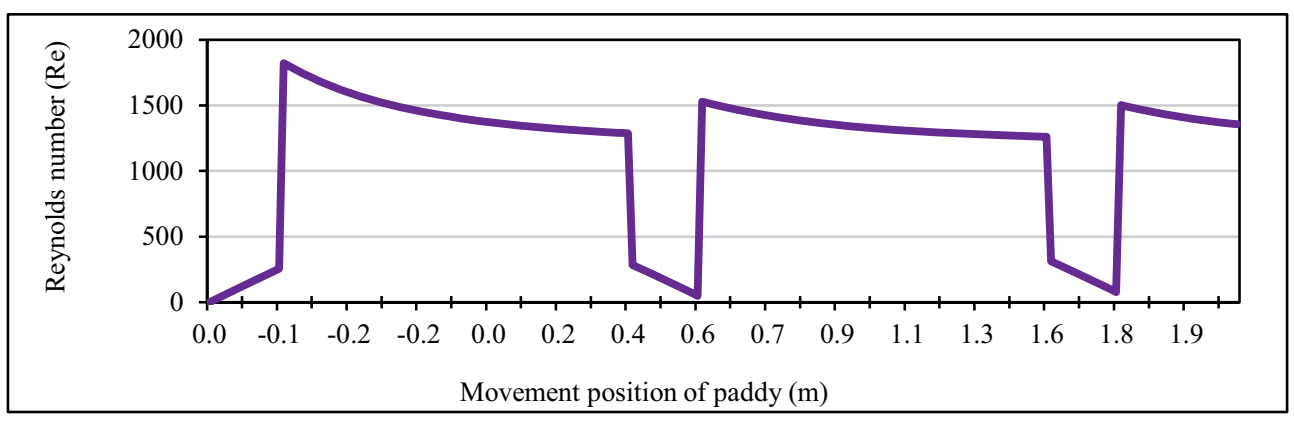

Fig. 8. Reynold Number of paddy during the distance in the tube. (Model III)

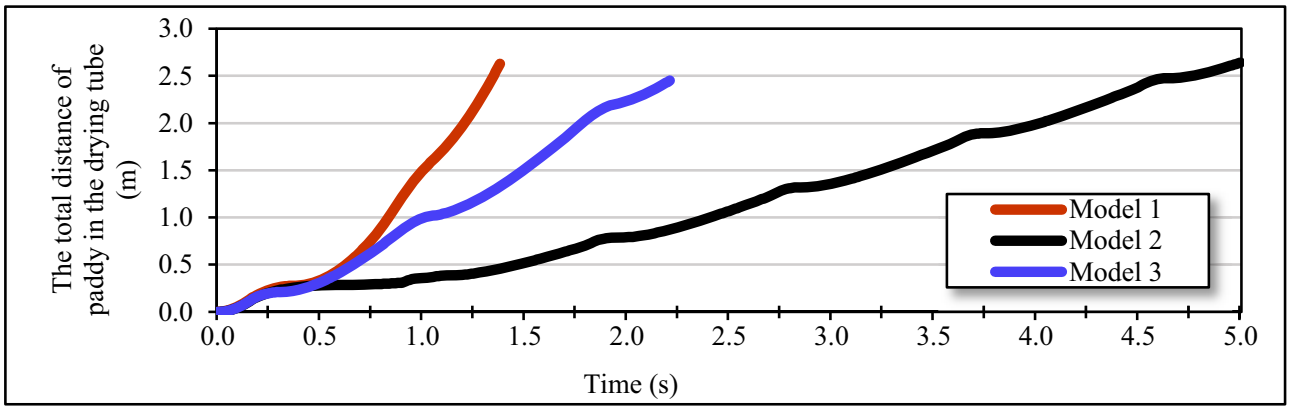

Fig. 9. Total distance of paddy in drying tubes during the travelling time. (3 models)

The number of travelling loop of paddy along the tube are 4, 12 and 6 times before reach the top end of tube for model I, II and III respectively. The computed maximum velocity of travelling of paddy in models I, II and III are $4.12,1.37$ and $1.85 \mathrm{~m} / \mathrm{s}$ respectively. When considering the Reynolds number, the models I, II and III give the most values from similar calculations with $1,837,1,816$ and 1,821 respectively. For the total distance of paddy movement, Model II can move the maximum total distance of $2.7 \mathrm{~m}$ at a time $5.0 \mathrm{~s}$. Model I can move a total distance of $2.6 \mathrm{~m}$ at a time $1.3 \mathrm{~s}$. And finally, Model III moving a total distance of $2.5 \mathrm{~m}$ at a time $2.2 \mathrm{~s}$. Based on various parameters from all of models, we agreed that model III was the closest to the actual movement in the system because it tried to gather the variables that had the most influence on the change of movement. However, it is necessary to further prove the true movement of paddy. We expected to collect the actual movement values from the prototype test together with particle motion analysis with EDEM software in our future work. 


\section{References}

1 S. Liu and M. Sakr, Renewable and Sustainable Energy Reviews. 19, 64 - 81(2013)

2 V. Chuwattanakul and S. Eiamsa-ard, Case Studies in Thermal Engineering. 13, (2019)

3 P. Eiamsa-ard, N. Piriyarungroj, C. Thainpong and S. Eiamsa-ard,Case studies in Thermal Engineerin. 3, 86 - 102 (2014)

4 E. F. Akyurek, K. Gelis, B. Sahin, and E. Manay, Experimental analysis for heat transfer of nanofluid with wire coil turbulators in a concentric tube heat exchanger, Results in Physics. 9, 376 - 389 (2018)

5 K. Nanan, C. Thianpong, M. Pimsarn, V. Chuwattanakul, and S. Eiamsa-ard, Applied Thermal Engineering. 114, 130 - 147 (2017)

6 S. Skullong, P. Promvonge, C. Thianpong, and N. Jayranaiwachira, Applied Thermal Engineering. 114, $130-147$ (2017)

7 M. M. K. Bhuiya, M. S. U. Chowdhury, M. Saha, and M. T. Islam, International Communications in Heat and Mass Transfer. 46, 49 - 57 (2013)

8 M. M. K. Bhuiya, A. S. M. Sayem, M. Islam, M. S. U. Chowdhury, and M. Shahabuddin, International Communications in Heat and Mass Transfer. 50, 25 - 33 (2014)

9 S. Skullong, P. Promvonge, N. Jayranaiwachira, and C. Thianpong,Chemical Engineering and Processing. 109, 164 - 177 (2016)

10 M. Gharekhani, M. Kashaninejad, A. Daraei Garmakhany and A. Ranjbari, Quality Assurance and Safety of Crops \& Foods. 187 - 197 (2013)

11 John M. Cimbala, Yunus A. Cengel, Essentials of Fluid Mechanics Fundamentals and Applications, International Edition (The McGraw-Hill Companies, 2008) 